SHORT REPORT

\title{
A case of Collet-Sicard syndrome associated with traumatic atlas fractures and congenital basilar invagination
}

\author{
H P Hsu, S T Chen, C J Chen, L S Ro
}

J Neurol Neurosurg Psychiatry 2004;75:782-784. doi: 10.1136/jnnp.2003.024083

An 18 year old man with congenital basilar invagination developed multiple lower cranial nerve $(C N)$ palsies including CN IX to XII after a traffic accident. Computed tomography of his skull base revealed a two part atlas Jefferson fracture. Normally, lower cranial nerves (CN IX-XII) pass through a space between the styloid process and the atlas transverse process. Atlas burst fractures rarely cause neurological deficits because of a greater transverse and sagittal diameter of the spinal canal at the atlas, and a tendency of the lateral masses to slide away from the cord after injury. However, when associated with a rare condition-congenital basilar invagination-atlas fractures can compromise the space and make CN IX-XII more vulnerable to compression injury. This report discusses the correlation between the anatomical lesions and clinical features of this patient.

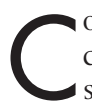
ollet-Sicard syndrome refers to unilateral lesions of cranial nerves (CN) IX, X, XI, and XII. ${ }^{12}$ This rare syndrome has been attributed to tumours of the skull base, coiling and dissections of the internal carotid artery, multiple myeloma, vasculitis, carotid fibromuscular dysplasia, shotgun injuries, idiopathic cranial polyneuropathy, atlas fractures, and occipital condyle fractures..$^{3-10}$ There is only one reported case of atlas Jefferson fracture causing Collet-Sicard syndrome in the English language literature of the Medline database from 1966 to $2003 .{ }^{11}$ Jefferson fractures are bursting injuries of the atlas, which rarely cause neurological deficits. This has been suggested to be a result of a greater transverse and sagittal diameter of the spinal canal at the first cervical spine, in addition to the mechanism of the lateral masses sliding away from the cord. Any neurological sequelae could be attributed to spinal cord damage or vertebral artery compromise rather than cranial nerve injury. The classic presentations of atlas fractures include neck pain, cervical muscle spasm, reduced range of neck motion, and head tilt. Compression of the greater occipital nerve causes suboccipital paresthesia or pain. ${ }^{11}$ We review the literature and will briefly discuss the probable mechanisms contributing to ColletSicard syndrome.

\section{CASE REPORT}

An 18 year old man with the chief complaint of neck pain, hoarseness, and dysphagia was admitted to the Chang Gung Memorial Hospital, Taiwan in November 1999. He had no previous systemic disorders except for a mild left hearing impairment of several years' duration. Three days before his admission, he was hit by a car while riding a motorcycle and was flung on to the ground. The patient had felt suboccipital discomfort and neck pain since then. Slurred speech, hoarseness, difficulty in swallowing, and easy choking took place rapidly. Physical examination revealed posterior cervical tenderness, a limited range of neck motion, absent gag reflex on the right side, the soft palate pulling to the left side, insensate oropharyngeal wall on the right side, tongue deviation to the right side, and mild weakness of the right trapezius muscle. The laryngoscopic examination showed right vocal cord palsy and pooling of secretions on the right side. Neck rotation could not be performed owing to neck pain and neck muscle guarding. The sternomastoid strength could not be checked because of neck immobilisation to prevent further cervical spine injury. An open mouth roentgenogram showed bilateral displacement of the lateral masses of the first cervical vertebra, with reference to the superior articular surface of the second cervical vertebra. Computed tomography of his skull base revealed a two part atlas fracture: one fracture through the right sided anterior arch and the other fracture through the left sided posterior arch (fig lA). Brain magnetic resonance imaging (MRI) demonstrated basilar invagination and rupture of the transverse ligament, without other anomalies such as Arnold-Chiari malformations, syringomyelia, syringobulbia, or hydrocephalus (fig 1B, C). He underwent external immobilisation with neck collar and reduction by traction. The residual sequela was slurred speech after an 18 month duration of follow up.

\section{DISCUSSION}

Multiple $\mathrm{CN}$ palsies are often a diagnostic challenge because the nerves can be affected at any site along their course. CN IX-XI exit the cranial vault through the jugular foramen, whereas CN XII leaves from the hypoglossal canal close to the occipital condyle. Near their points of exit, CN IX-XII lie between the transverse process of the atlas medially and the styloid process of the skull laterally. Zielinski et al identified the mechanism by which atlas fractures could produce cranial nerve symptoms. ${ }^{9}$ Through their study of cadavers, they found that there was only $8-10 \mathrm{~mm}$ of space between the transverse process of the atlas and the styloid process. CN IX-XII pass through this narrow space (fig $2 \mathrm{~A}$ ). If the atlas were abnormally displaced laterally after a Jefferson fracture, this space would be reduced to nearly nothing and lower $\mathrm{CN}$ palsies would be likely to develop.

Fractures of the atlas are rare and comprise only $2 \%$ of all spinal injuries. ${ }^{12}$ The mechanisms of injury include motor vehicle accidents, falls, pedestrian impacts, hang-gliding, skateboarding, diving injuries, waterskiing accidents, and an equestrian accident. ${ }^{13-15}$ Atlas fractures usually occur as a result of axial compression loads, which result in the transmission of forces through the occiput to the cervical spine via the lateral masses of $\mathrm{Cl}$. The forceful separation of the lateral masses of $\mathrm{Cl}$ also places the transverse ligaments at risk for rupture or avulsion, which could result in atlantoaxial instability. ${ }^{16}$ Plain radiography and computed tomography can be used to investigate the presence of an

Abbreviations: $\mathrm{CN}$, cranial nerves; $\mathrm{MRI}$, magnetic resonance imaging 

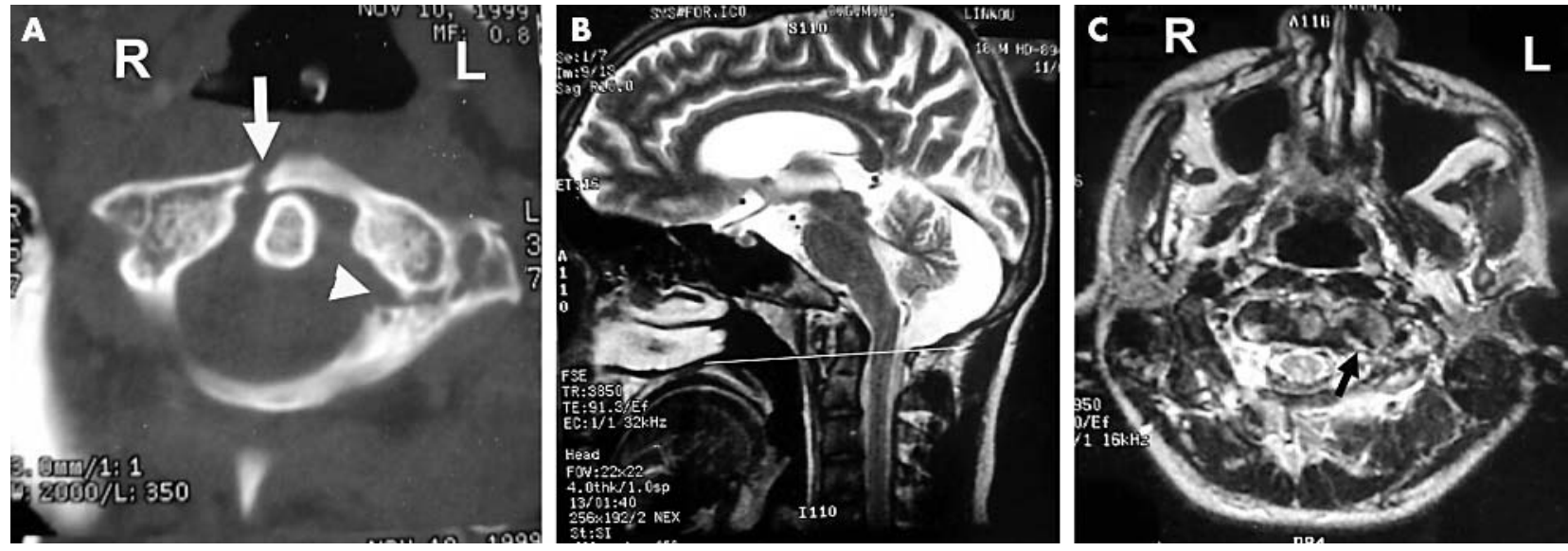

Figure 1 (A) Computed tomography of the skull base shows a two part atlas fracture: one fracture through the right sided anterior arch (arrow) and the other fracture through the left sided posterior arch (arrowhead). (B) Brain magnetic resonance imaging (MRI) on T2 weighted image shows basilar invagination. The odontoid process is entirely above Chamberlain's line (a line from the hard palate to base of skull). (C) Brain MRI on T2 weighted image confirms tearing of the transverse ligament (arrow). Ligament rupture appears as a region of disruption with high signal intensity.

atlas fracture. MRI of the cervical spine may facilitate the assessment of the surrounding soft tissue and the integrity of the transverse ligament. ${ }^{17}$ Tears of the transverse ligament appear as a loss of anatomical continuity of the ligament

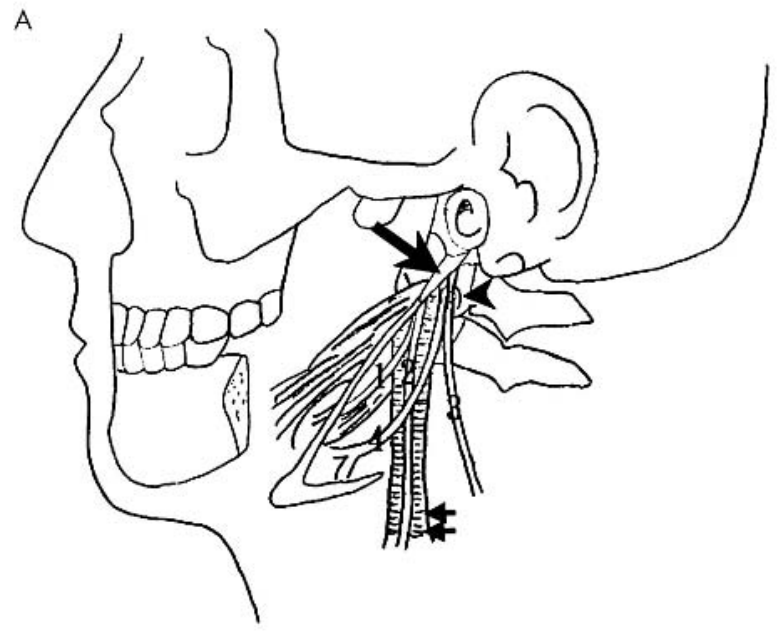

B

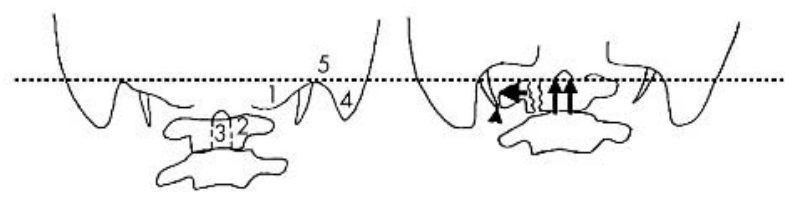

Figure 2 (A) The schematic drawing shows CN IX-XIl passing through the narrow space between the styloid process (arrow) and the transverse process of the atlas (arrowhead). $\mathrm{CN}$, cranial nerves; 1 , the ninth cranial (glossopharyngeal) nerve; 2 , the 10th cranial (vagus) nerve; 3 , the 11 th cranial (accessory) nerve; 4 , the 12th cranial (hypoglossal) nerve; double arrow, the internal carotid artery. (B, left) $A$ normal basal skull shows that occipitoatlantic joints and the tip of the odontoid process are well below Fischgold's digastric line (dotted line). 1, occipital condyle; 2 , atlas; 3, odontoid process; 4, mastoid; 5, digastric groove. (B, right) Occipitoatlantic joints and the tip of the odontoid process are protruding above Fischgold's digastric line in basilar invagination. After atlas fracture, both basilar invagination (double arrow) and lateral displacement of the lateral mass (arrow) can co-compromise the narrow space through which CN IX-XII pass (arrowhead). containing regions of high signal intensity compared with the homogeneous low signal intensity of the normal ligament on gradient echo MRI. ${ }^{18}$ Treatment should be aimed at stabilisation of the symptoms and prevention of further neurological damage.

Basilar invagination is a developmental defect implying protrusion of the vertebral column into the skull base. Basilar invagination might be associated with Chiari malformations, syringobulbia, and syringomyelia. The prevalence of neurodysgenesis is between $25 \%$ and $30 \%$ in basilar invagination. The neurological deficits are from direct compression of the neural tissue by bone and soft tissue at the craniovertebral junction, or a compromise of the vertebral anterior spinal and perforating arteries to the cervicomedullary junction. Minor trauma may set off a pattern of symptoms and signs that progress at a speedy pace. ${ }^{19}$ In basilar invagination, the odontoid process is above Chamberlain's line, which joins the hard palate to the opisthion on radiological images. A minor degree of basilar invagination may produce no neurological symptoms. However, combined with an atlas fracture, the lower $\mathrm{CN}$ are vulnerable to be stretched and compressed because of both upward indentation of the skull base and lateral displacement of the atlas lateral mass (fig 2B).

When a subject has Collet-Sicard syndrome after a traumatic injury, we should take atlas fractures associated with basilar invagination into account. Other cervical spine injuries (for example, Hangman fracture or cervical spine subluxation/dislocation) have also been reported to result in CN palsies. ${ }^{9}$ This report highlighted the importance of neurological examinations and the anatomical relation of the posterior fossa, skull base, and upper cervical spine.

\section{Authors' affiliations}

H P Hsu, S T Chen, L S Ro, Department of Neurology, Chang Gung Memorial Hospital and Chang Gung University, 199 Tun Hwa North Road, Taipei, Taiwan 10591

C J Chen, Department of Radiology, Chang Gung Memorial Hospital and Chang Gung University

\section{Competing interests: none declared}

Correspondence to: Dr L-S Ro, Department of Neurology, Chang Gung Memorial Hospital and Chang Gung University, 199 Tun Hwa North Road, Taipei, Taiwan 10591; cgrols@adm.cgmh.org.tw

Received 21 July 2003

In revised form 16 September 2003

Accepted 1 October 2003 


\section{REFERENCES}

1 Collet FJ. Sur un nouveau syndrome paralytique pharyngo-larynge par blessure de guerre (hemiplegie glosso-laryngo-scapulo-pharyngee). Lyon Medical 1915;124:121-9.

2 Sicard JA. Syndrome du carrefour condylodechire posterieur (type pur de paralysie des quatre derniers nerfs craniens). Marseille Medical 1917;53:385-97

3 Hashimoto T, Watanabe $O$, Takase $M$, et al. Collet-Sicard syndrome after minor head trauma. Neurosurgery 1988;23:367-70.

4 Heckmann JG, Tomandl B, Duhm C, et al. Collet-Sicard syndrome due to coiling and dissection of the internal carotid artery. Cerebrovasc Dis 2000;10:487-8

5 Larson WL, Beydoun A, Albers JW, et al. Collet-Sicard syndrome mimicking neuralgic amyotrophy. Muscle Nerve 1997;20:1173-7.

6 Prick MJ, Verhagen WI. The Collet-Sicard syndrome as a complication of cardiovascular surgery. J Neurol Neurosurg Psychiatry 1992;55:741

7 Paparounas K, Gotsi A, Apostolou F, et al. Collet-Sicard syndrome disclosing glomus tumor of the skull base. Eur Neurol 2003:49:103-5.

8 Tappin JA, Satchi G, Corless JA, et al. Multiple myeloma presenting as the Collet-Sicard syndrome. J Neurol Neurosurg Psychiatry 1996;60:14.

9 Zielinski CJ, Gunther SF, Deeb Z. Cranial-nerve palsies complicating Jefferson fracture. A case report. J Bone Joint Surg Am 1982;64:1382-4.
10 Sharma BS, Mahajan RK, Bhatia S, et al. Collet-Sicard syndrome after closed head injury. Clin Neurol Neurosurg 1994;96:197-8

11 Connolly B, Turner C, DeVine J, et al. Jefferson fracture resulting in ColletSicard syndrome. Spine 2000;25:395-8.

12 Levine AM, Edwards CC. Treatment of injuries in the C1-C2 complex. Orthop Clin North Am 1986;17:31-44.

13 Fowler JL, Sandhu A, Fraser RD. A review of fractures of the atlas vertebra. J Spinal Disord 1990;3:19-24.

14 Hadley MN, Dickman CA, Browner CM, et al. Acute traumatic atlas fractures: management and long term outcome. Neurosurgery 1988;23:31-5.

15 Kesterson L, Benzel E, Orrison W, et al. Evaluation and treatment of atlas burst fractures (Jefferson fractures). J Neurosurg 1991;75:213-20.

16 Bayar MA, Erdem Y, Ozturk K, et al. Isolated anterior arch fracture of the atlas: child case report. Spine 2002;27:E47-9.

17 Judd DB, Liem LK, Petermann G. Pediatric atlas fracture: a case of fracture through a synchondrosis and review of the literature. Neurosurgery 2000;46:991-4.

18 Dickman CA, Mamourian A, Sonntag VK, et al. Magnetic resonance imaging of the transverse atlantal ligament for the evaluation of atlantoaxial instability. J Neurosurg 1991;75:221-7.

19 Julian R. Youmans neurological surgery. Philadelphia: WB Saunders, 1996.

\section{NEURONLINE}

\section{We move: www.wemove.org}

T his snappily named site claims to be the internet's most comprehensive resource for movement disorder information and the hub of movement disorder activities on the web. It is certainly a very well presented and useful site. There are a number of free services on offer. There is a movement disorder research news email update service (E-MOVE), links to other, mainly American, sites and support groups, both a chat room and forum (for which you have to register), and a link to movement disorder virtual university (MDVU). This is a closely related site that has an even snappier appearance than the original We move site but actually contains much of the same information under the topic headings. On the We move site these are listed on 21 buttons down the left edge. There is an interesting mix of the expected diseases, such as Parkinson's; general, non-disease specific problems, such as tremor (which then covers paediatric tremor); and other slightly unexpected topics such as spasticity, Huntington's disease, and Rett syndrome. The information on each topic is well organised and reasonably current. The site is funded by a long list of pharmaceutical companies and the treatment section of each subject is peppered with their branded products in addition to the generic names. The American parentage of the site is also reflected in the

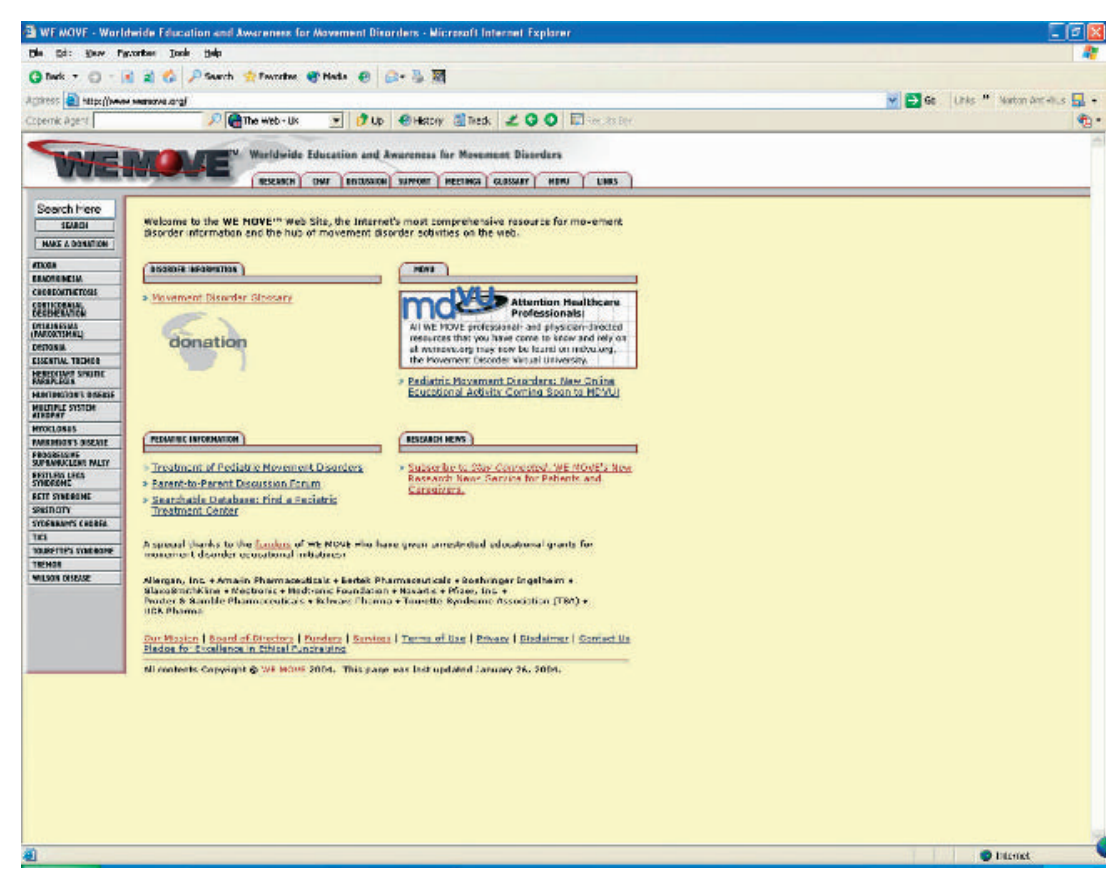

suggested use of drugs unavailable in the UK, such as tolcapone. Strangely, considering its title and subject, what the site lacks is movement in the form of video clips. There is an animated clip of how botulinum toxin works but this took long enough, across a broadband connection, for me to make a cup of tea before it started. Overall though, it is a great place to start on the web for movement disorders information.

M Sadler

Department of Neurology, Derriford Hospital, Derriford, Plymouth PL6 8DH, UK martin.sadler@phnt.swest.nhs.uk.

doi: 10.1136/jnnp.2003.012963 